\title{
Comparative Analysis of the Selection of Lay-Up Stacking of Polymer Composite Load-Bearing Elements for the Tail Section of Fuselage Structure of the Light Aircraft
}

\author{
Tun Lin Htet $^{1, *}$ and P.V. Prosuntsov ${ }^{1}$ \\ ${ }^{1}$ Bauman Moscow State Technical University, 105005, Moscow, Russia
}

\begin{abstract}
The problem of the selecting the optimal lay-up stacking of polymer composite materials for the load-bearing elements of the rear part of fuselage structure is considered. The comparison of two approaches to the design of the load-bearing elements is carried out. The first of them is the use of multilayered composite material for the load-bearing elements, the stacking angles of which is selected from a given discrete set, and the second is the use of composite material with a continuous range of variables in fabric lay-up angles. As a result design optimization, it is shown that using an optimization method with a continuous range of lay-angles allows reducing the weight of the load-bearing elements by $12.79 \%$
\end{abstract}

\section{Introduction}

The task of reducing the weight of aircraft structures is one of the most important at the entire stage of its development. An effective tool for reducing the weight of aircraft structures is the use of composite materials with high specific strength and stiffness characteristics. The use of composites should be based not just on the mechanical replacement of traditional metal materials with composite materials, but take into account their features - primarily the anisotropy of characteristics. The creation of composite structures should be based on the widespread use of modern methods of numerical modeling and optimization $[1,2]$.

The aim of this work is to reduce the weight of the composite load-bearing elements of the fuselage of a light aircraft while maintaining their required strength using optimization methods.

\section{Results of previous studies}

The object of research in this paper is the tail section of the DA-62 aircraft, which is a twinengine monoplane with a $T$-shaped tail. The fuselage of the DA-62 aircraft is a semimonocoque and consists of a skin and four oval shaped ribs made of carbon fiber plastic [3, 4].

\footnotetext{
* Corresponding author: tunlinhtet64509@gmail.com
} 
In the previous research [5], the problem of choosing the locations and width of the ribs of the fuselage structure was solved using parametric optimization. As a result, the location coordinates and the width of the elements of the ribs were determined, providing maximum structural rigidity with a minimum level of stress in the load-bearing elements (Fig. 1-a). Further, using the topological optimization method, the shapes of the ribs were determined (Fig. 1-b). At the same time, the loads acting on the aircraft when performing maneuvers in the horizontal and vertical planes were taken into account, considering the requirements of Airworthiness Standards [5].

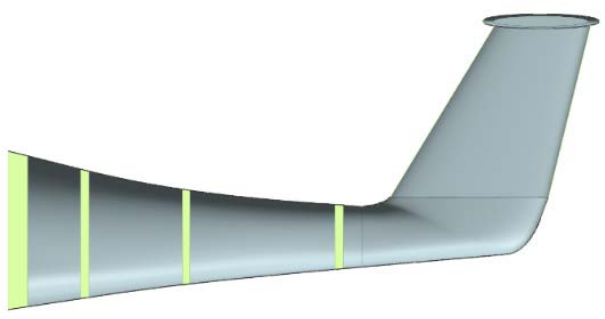

(a) The location and width of the ribs, determined from the results of parametric optimization
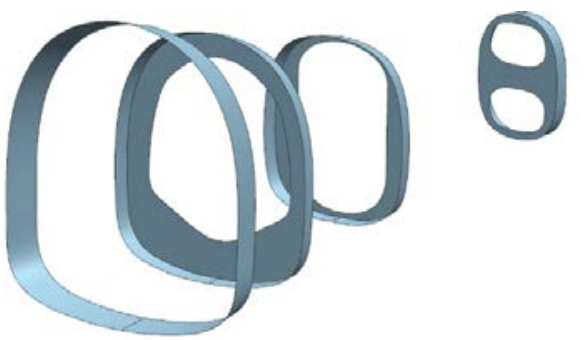

(b) The shapes of ribs, obtained from the results of the topological optimization

Fig. 1. Results of designing the load-bearing elements of the tail section of the aricraft

Polymer composite material based on epoxy resin and carbon fabric was selected as the applied materials in the design of the DA-62 aircraft, which allowed for high strength and low weight of the structure. The characteristics of carbon fiber plastics are given in Table 1.

Table 1. Physio-mechanical properties of carbon fiber plastic

\begin{tabular}{|l|l|l|}
\hline \multicolumn{1}{|c|}{ Characteristics } & Unit & Value \\
\hline Density & $\mathrm{kg} / \mathrm{m}^{3}$ & 1480 \\
\hline Young's Modulus along fiber, $E_{1}$ & $\mathrm{GPa}$ & 91.82 \\
\hline Young's Modulus across fiber, $E_{2}$ & $\mathrm{GPa}$ & 9.0 \\
\hline Shear Modulus, $G_{12}$ & $\mathrm{GPa}$ & 19.5 \\
\hline Tensile strength & $\mathrm{MPa}$ & 829 \\
\hline Compressive strength & $\mathrm{MPa}$ & 439 \\
\hline Shear strength & $\mathrm{MPa}$ & 120 \\
\hline Thickness of single layer & $\mathrm{mm}$ & 0.25 \\
\hline
\end{tabular}

\section{Optimization of the lay-up stacking of the composite structure}

When developing a composite structure, an important issue is the selection of lay-up stacking, on which the strength and weight of the structure being created significantly depends.

There are two possible approaches to the design of composite load-bearing elements. The first of them is the use of a multilayered composite material for the manufacture of ribs, the lay-up angles of which are selected from a predetermined discrete set, and the second is the use of composite material with a continuous range of variables of the orientation of lay-up fabrics. In both cases, the optimized parameters are the lay-up angles of the layers. The first approach makes it possible to significantly simplify the manufacturing technology and, accordingly, reduce the cost of the created structure, and the second can potentially lead to a reduction in the mass of the structure at the cost of some complication of the technological 
process, but there are currently no accurate estimates of the mass effectiveness of this approach.

To take into account the features associated with the use of anisotropic composite materials in the ribs of the fuselage structure, the stresses in individual layers of the composite structure were analyzed in ANSYS ACP PrePost software package.

It was taken into account that the ribs, except for the first one, consist of two parts: a oval shaped and a vertical part, which were separately considered when choosing lay-up angles. It was considered, that the layers of composite material are formed from fabric, the direction of the warp fibers for which is shown in Figure 2.

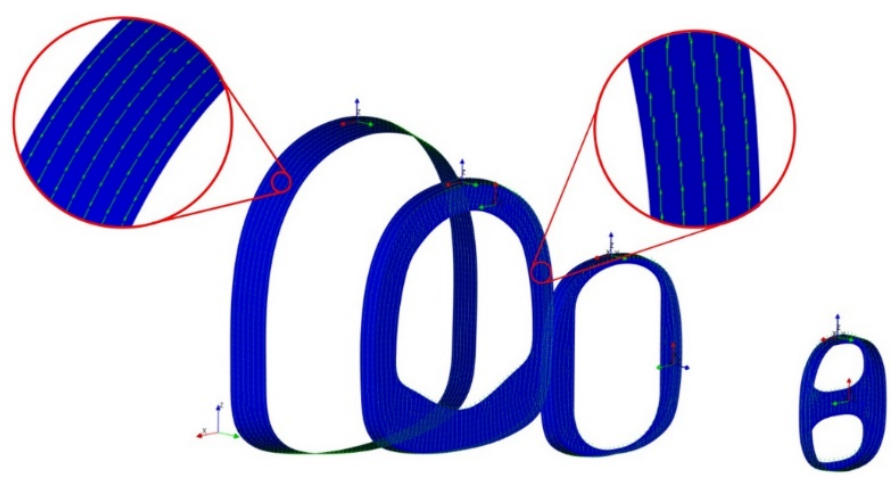

Fig. 2. Orientation of the main fabrics of the layers of the composite materials

When using the first approach to the design of ribs, the orientation angles of individual layers were limited to the values $0^{\circ}, 90^{\circ},+45^{\circ}$ and $-45^{\circ}$, which significantly reduces the complexity of manufacturing ribs. The total number of layers for each variant was assumed 20, which corresponded to the results of the stress-strain state analysis performed for solid models of ribs. The variable parameters were the stacking lay-up angles. When solving the optimization problem, the level of maximum stresses in the layers of a composite material was limited to $175 \mathrm{MPa}$, which corresponded to a safety factor of 2 . The considered variants for the lay-up stacking of multilayered composite ribs are presented in Table 2 .

Table 2. Considered variants of the lay-up stacking in the first approach

\begin{tabular}{|c|c|c|c|c|c|c|}
\hline \multirow{2}{*}{$\begin{array}{c}\text { No. } \\
\text { variants }\end{array}$} & \multirow{2}{*}{$\begin{array}{c}\text { Oval shaped } \\
\text { elements }\end{array}$} & \multirow{2}{*}{$\begin{array}{l}\text { Vertical } \\
\text { elements }\end{array}$} & \multicolumn{4}{|c|}{ Maximum von-mises stress in layers of ribs, $\mathrm{MPa}$} \\
\hline & & & $1^{\text {st }} \mathrm{rib}$ & $2^{\text {nd }} \mathrm{rib}$ & $3^{\text {rd }}$ rib & $4^{\text {th }}$ rib \\
\hline 1 & {$[0]_{20}$} & {$[0]_{20}$} & 130.66 & 287.79 & 138.65 & 161.84 \\
\hline 2 & {$[0]_{20}$} & {$[0 /+45]_{10}$} & 129.71 & 229.23 & 143.56 & 210.2 \\
\hline 3 & {$[0 /+45]_{10}$} & {$[0 /+45]_{10}$} & 114.86 & 234.81 & 133.80 & 214.30 \\
\hline 4 & {$[0]_{20}$} & $\begin{array}{c}{[0 /+45 / 90 /-} \\
45 / 0]_{4}\end{array}$ & 129.83 & 314.00 & 134.56 & 194.48 \\
\hline 5 & $\begin{array}{c}{[0 /+45 / 90 /} \\
45 / 0]_{4}\end{array}$ & $\begin{array}{c}{[0 /+45 / 90 /-} \\
45 / 0]_{4}\end{array}$ & 118.51 & 321.59 & 158.63 & 197.97 \\
\hline 6 & {$[ \pm 45]_{10}$} & {$[ \pm 45]_{10}$} & 135.11 & 198.65 & 133.87 & 200.13 \\
\hline 7 & {$[0]_{20}$} & {$[ \pm 45]_{10}$} & 129.21 & 225.68 & 130.31 & 197.85 \\
\hline
\end{tabular}


According to table 2, the stress values are minimal for variant No. 6. However, the maximum stresses in $2^{\text {nd }}$ and $4^{\text {th }}$ ribs exceed the permissible values, so the number of layers in these ribs was increased by one pair with lay-up angles $\pm 45^{\circ}$. The results of the simulation, taking into account the correction of the number of layers of $2^{\text {nd }}$ and $4^{\text {th }}$ ribs, are shown in Table 3 .

Table 3. Optimal lay-up angles for each rib in the first approach

\begin{tabular}{|c|c|c|c|c|c|}
\hline \multirow{2}{*}{$\begin{array}{c}\text { No. of } \\
\text { ribs }\end{array}$} & \multicolumn{2}{|c|}{ Lay-up stacking } & Maximum von- & Maximum \\
\cline { 2 - 3 } & $\begin{array}{c}\text { Oval shape } \\
\text { elements }\end{array}$ & $\begin{array}{c}\text { Vertical } \\
\text { elements }\end{array}$ & $\begin{array}{c}\text { MPa stress, } \\
\text { MPa }\end{array}$ & $\begin{array}{c}\text { Weight, } \\
\text { thickness, mm }\end{array}$ & kg \\
\hline 1 & {$[ \pm 45]_{10}$} & - & 134.82 & 5 & 3.4708 \\
\hline 2 & {$[ \pm 45]_{11}$} & {$[ \pm 45]_{11}$} & 169.96 & 5.5 & 3.6657 \\
\hline 3 & {$[ \pm 45]_{10}$} & {$[ \pm 45]_{10}$} & 134.00 & 5 & 1.6291 \\
\hline 4 & {$[ \pm 45]_{11}$} & {$[ \pm 45]_{11}$} & 169.30 & 5.5 & 1.1264 \\
\hline
\end{tabular}

It can be seen that the total weight of the four ribs is $9.4609 \mathrm{~kg}$.

Using the second approach, the problem of optimizing the lay-up angles of the composite material, which are in a continuous range from $-90^{\circ}$ to $+90^{\circ}$, is solved, for which the ANSYS optiSLang software package was used. At the same time, taking into account the symmetry of possible loads in the longitudinal plane of the aircraft, symmetrical lay-up stacking were used, which was ensured by the use of pairs of layers.

The initial value of the stacking angles for all layers of each group of elements was $0^{\circ}$. The set of variable parameters and constraints corresponded to the first approach. In the event that when solving the optimization problem, the maximum stress level was significantly lower than the specified one, then the number of material layers was reduced. Table 4 shows the optimal lay-up angles for the circular and vertical parts of all ribs.

Table 4. Optimal lay-up stacking for each ribs in the second approach

\begin{tabular}{|c|c|c|c|c|c|}
\hline \multirow{2}{*}{$\begin{array}{c}\text { No. of } \\
\text { ribs }\end{array}$} & \multicolumn{2}{|c|}{ Lay-up stacking } & $\begin{array}{c}\text { Maximum } \\
\text { von-mises } \\
\text { stress, MPa }\end{array}$ & $\begin{array}{c}\text { Maximum } \\
\text { thickness, } \\
\mathrm{mm}\end{array}$ & $\begin{array}{c}\text { Weight, } \\
\mathrm{kg}\end{array}$ \\
\hline 1 & {$[0 / \pm 30 / \pm 60 / \pm 10]_{2}$} & - & 152.84 & 3.5 & 2.4295 \\
\hline 2 & $\begin{array}{c}{[ \pm 30 / \pm 60 / \pm 90 / \mp 50 / \mp 3} \\
0]_{2}\end{array}$ & $\begin{array}{c}{[+35 /+30 /-65 /-50 /} \\
+40 /+40 /+30 /+35 / \\
-30 /-45 /+50]_{2}\end{array}$ & 178.19 & 5.5 & 3.5446 \\
\hline 3 & {$[0 / 0 / \pm 50 / \pm 65]_{2}$} & $\begin{array}{c}{[-40 / 0 / 0 / \mp 55 /} \\
\mp 48 /+35]_{2}\end{array}$ & 162.23 & 4 & 1.1422 \\
\hline 4 & {$\left[\begin{array}{l}{[ \pm 6 / \pm 6 / \pm 12 / \mp 13 / \mp 10]} \\
2\end{array}\right.$} & $\begin{array}{c}{[\mp 3 / 0 / 0 / \mp 82 / \mp 24 / \mp} \\
52] 2\end{array}$ & 165.51 & 5 & 1.0240 \\
\hline
\end{tabular}

The total weight of the four ribs is $8.1403 \mathrm{~kg}$. Figure 3 shows the distribution of the principal stresses in the layers of the composite material for each rib. Thus, based on the results of optimization process, a new structural of load-bearing elements of the tail section of the aircraft is proposed, the mass of all four ribs of which is $12.79 \%$ less than that of the design variant, obtained using the first approach. 


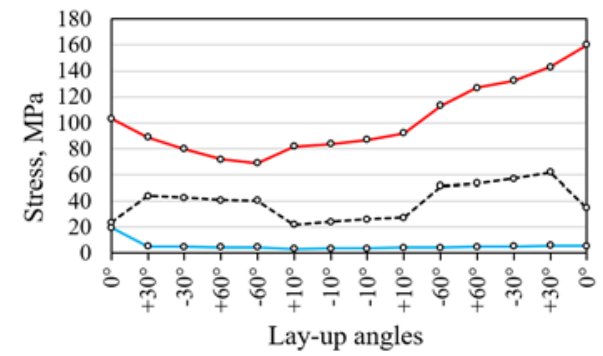

(a)

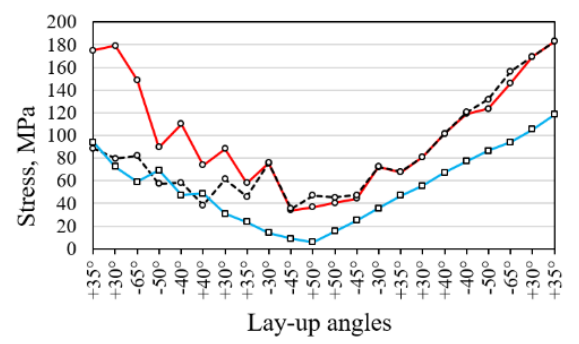

(c)

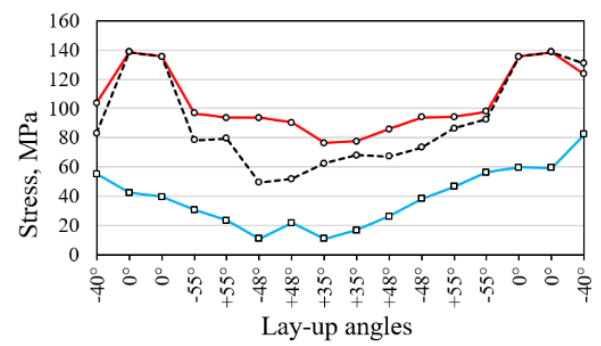

(e)

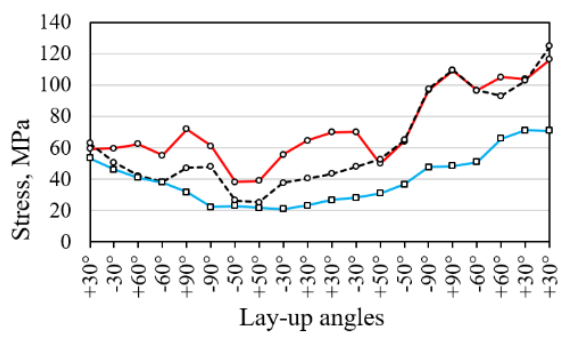

(b)

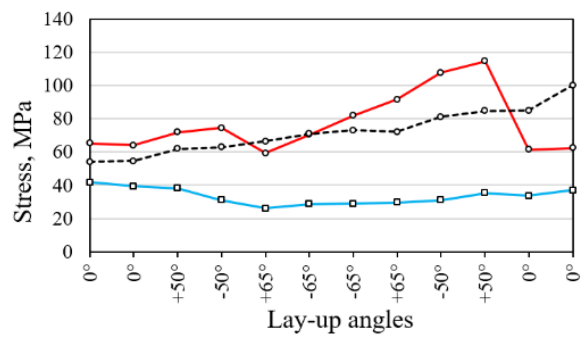

(d)

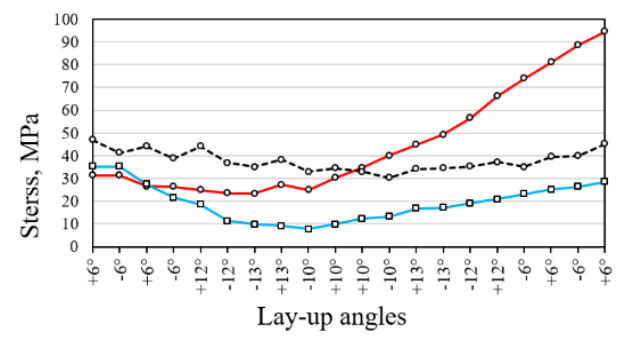

(f)

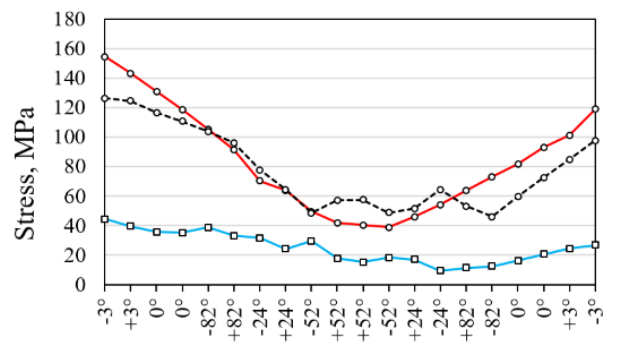

Lay-up angles

(g)

\section{$\multimap$ Maximum principal stress, $\sigma 1$ \\ $\longrightarrow$ Minimum principal stress, $\sigma 3$}

Fig. 3. Distribution of the principal stresses in the layers of composite ribs: a) oval-shaped part of the $1^{\text {st }}$ rib, b) oval-shaped part of the $2^{\text {nd }}$ rib, c) vertical part of the $2^{\text {nd }}$ rib, d) oval-shaped part of the $3^{\text {rd }}$ rib, e) vertical part of the $3^{\text {rd }}$ rib, f) oval-shaped part of the $4^{\text {th }}$ rib, f) vertical part of the $4^{\text {th }}$ rib

In addition, a verification analysis of the stress-strain state was carried out in ANSYS Static Structural, which confirmed the operability of the structure (Fig. 4). 

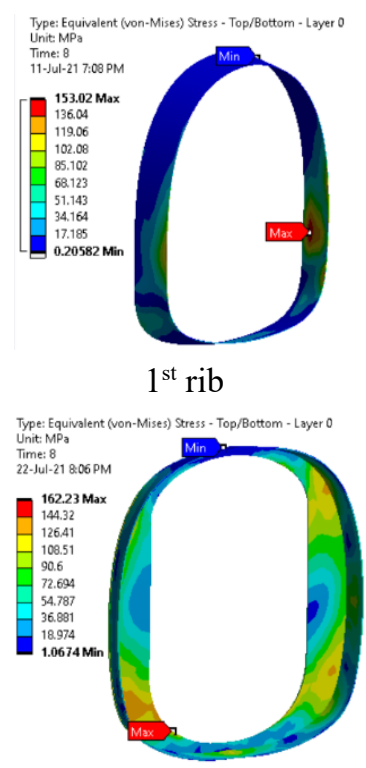

$3^{\text {rd }}$ rib

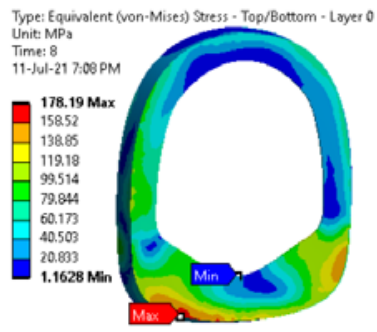

$2^{\text {nd }} \mathrm{rib}$

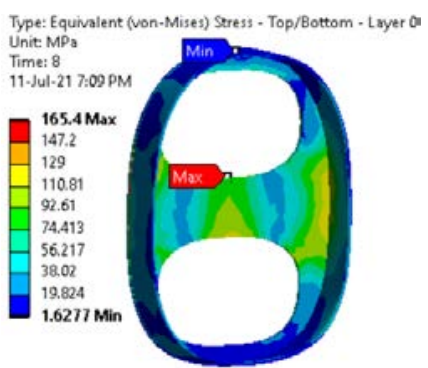

$4^{\text {th }}$ rib

Fig. 4. Distribution of maximum von-mises stresses in the most loaded layers of the composite material for various ribs with optimized lay-up stacking, MPa

\section{Conclusion}

Two approaches to the selection of optimal lay-up stacking for composite load-bearing elements of the fuselage structure of a light aircraft are proposed. In the first approach, a fixed set of typical angles is used, and in the second, the stacking angles are determined from parametric optimization method with a continuous range of variables. It is shown that the use of an approach based on parametric optimization leads to a decrease in the weight of the structural elements of the tail section of the aircraft by $12.79 \%$ while maintaining its sufficient strength.

\section{Reference}

1. T.G. Ageeva, E.N. Dudar, S.V. Reznik, Complex approach to the construction design for reusable spacecraft, Tekhnologiya mashinostryeniya 2021 (3), pp. 34-36 (2021)

2. S.V. Reznik, A.S. Esetbatyrovich, Composite air vehicle tail fins thermal and stressstrain state modeling, AIP Conference Proceedings 2319 (2021)

3. DA 62: Diamond Aircraft [URL] - https://www.diamondaircraft.com/en/privatepilots/aircraft/da62/overview/

4. Y.U. Suslov, Letnaya ekspluatatsiya system i tekhnologiya raboty ekipazha samoleta DA 42 [Flight operation of systems and working technology of the DA 42 aircraft]: Textbook, Ulyanovsk: UBAU GA (I), p.187 c (2010) (in Russian)

5. Tun Lin Htet, P.V. Prosuntsov, Parametric and topology optimization of polymer composite load bearing elements of rear part of aircraft fuselage structure, AIP Conference Proceedings 2318, 020008 (2021) 